\title{
BEARD, Mary. SPQR: Uma história da Roma Antiga. Trad. Luis Reyes Gil. São Paulo: Planeta, 2017. 576 p. ISBN 978-85-422-0940-2
}

\author{
Azenathe Pereira Braz*
}

Recebido em: 09/10/2018

Aprovado em: 02/11/2018

$\mathrm{E}$ m seu título, o livro de Mary Beard apresenta a abreviatura de uma famosa expressão que remonta a duas importantes instituições da Roma Antiga: Senatus Populusque Romanus (O Senado e o Povo Romano). É uma das siglas mais antigas da história, permanecendo inscrita nos lugares públicos, em latas de lixo e tampas de esgoto da atual cidade de Roma, e que aqui transmite brevemente o tema da obra. Já o subtítulo nos oferece uma noção do que propõe o livro: uma versão sobre como uma pequena aldeia no centro da Itália pôde se tornar uma potência mundial da Antiguidade.

Mary Beard é uma inglesa especialista em estudos clássicos, catedrática da Universidade de Cambridge e professora de literatura antiga na Royal Academy of Arts, editora de clássicos do The Times Literary Supplement. Possui várias publicações, mas poucas estão traduzidas para a língua portuguesa: Pompéia. A vida de uma cidade romana; Antiguidade Clássica; Mulheres e Poder. Um manifesto. Esses livros, juntamente com SPQR: Uma história da Roma Antiga, que esteve cerca de um ano entre os livros mais vendidos dos EUA e Grã Bretanha, figuram na lista de best-sellers da autora. Suas obras - um blog, participações ativas no Twitter, frequentes aparições na mídia, apresentação de documentários na BBC - renderam a Beard o status de "intelectual, mas acessível", sendo hoje considerada uma das historiadoras mais famosas do Reino Unido.

Com uma bagagem de décadas de estudos, a autora apresenta o estudo e a produção científica sobre Roma Antiga como algo extremamente desafiador: trata-se de um trabalho contínuo, visto que a historiografia tem apresentado constantes renovações nas pesquisas, abordagens inovadoras, diferentes maneiras de interpretar os dados e novas indagações, o que acaba tornando a busca do conhecimento sobre a história da Roma Antiga o empreendimento de uma vida.
* Mestranda do

Programa de

Pós-Graduação

em História, Universidade Federal de Goiás. Bolsista da Coordenação de Aperfeiçoamento de Pessoal de Nível Superior, CAPES. azenathebraz@gmail. com (iD) 
Assim sendo, $S P Q R$ mostra o resultado de pesquisas realizadas ao longo de quarenta anos que, segundo a autora, são a sua contribuição para um projeto maior, movido por uma convicção pessoal de que o diálogo com a Roma Antiga ainda é importante para compreensão de muitos aspectos da sociedade ocidental.

Em mais de quinhentas páginas, Beard amplia a discussão das concepções criadas no decorrer do tempo a respeito de como Roma se expandiu e estabeleceu suas conquistas. Começando sua análise pelos meados do século I a. C., no conflito entre Catilina e Cícero, a autora traça um paralelo com questões que ainda hoje têm lugar na política, fazendo questionamentos tais como: será legítimo eliminar terroristas à margem dos devidos processos legais? O quanto dos direitos civis deve ser sacrificado em nome da segurança interna? Ao descrever os acontecimentos de $63 \mathrm{~d}$. C. que ficaram conhecidos como uma crise seguida de ameaça de conspiração terrorista no cerne do establishment romano, a autora desafia a perspectiva dominante de Cícero a respeito do episódio da insurreição e, com evidências contemporâneas demonstradas por estudos arqueológicos e literários, apresenta a hipótese de Catilina não ser realmente o vilão da história.

A crítica da autora à interpretação dominante encontra-se no eixo argumentativo de toda a obra: é sempre bom estar alerta ao outro lado da história; a conspiração é sempre representada de acordo com o alinhamento ideológico do autor e o clima político da época. Para a autora, o conflito entre Cícero e Catilina ainda age como modelo para nossas discussões e a eloquência de Cícero ainda é moldadora da linguagem política contemporânea, são "ecos desconfortáveis dos nossos próprios tempos" (p. 53).

A obra completa está dividida em dez capítulos. Entre o prólogo e epílogo, o livro aborda o primeiro milênio de Roma - em um retorno às descobertas arqueológicas em confronto com a tradição literária -, e analisa a plausibilidade das hipóteses sob diversos aspectos. Começando pela datação da cidade de Roma; passando pelas ficcionais personagens Rômulo e Remo; a quantidade de reis e a forma como seu poder era concebido (mais como comandantes); a transição do governo; a influência do Senado; o povo e a constituição do Império; chegando ao processo que levou à gradual transformação do imperador em um deus.

Para o período em que a cidade de Roma esteve sob o domínio dos reis, as escavações que levaram à descoberta da palavra rex na pedra do Fórum são o ponto de partida da autora, que segue a História de Tito Lívio, porém acolhe o ponto de vista de que o período monárquico da história romana se insere na fronteira entre mito e história.

Após um preâmbulo analítico sobre a Roma primordial, o que lemos é um relato sobre o fim da monarquia e o inicio da República, ao explicar como o termo "rei" se tornou depreciativo e como a liberdade se tornou o símbolo do novo modelo de governo. A autora demonstra a sobrevivência dessa concepção ao desenvolver a ideia de que a República romana foi fundada na libertas e sua repercussão foi perceptível em movimentos radicais dos séculos seguintes na Europa e na América do Norte (p. 127).

Nos capítulos seguintes, são desenvolvidas considerações sobre a transição da Monarquia para a República. A autora assinala uma fluidez característica das pesquisas na área e analisa os fatos e interpretações sobre como esse processo se estabeleceu de forma 
gradual, confusa e com várias reinvenções. A formação e o fortalecimento das instituições características da Res Publica romana evidenciam que quanto mais se remonta ao passado da história de Roma Antiga, mais oscilantes as regras se tornam.

A partir do século I da nossa era, os eruditos romanos começam a estudar seu passado, e é a partir dessas histórias - que sobreviveram em documentos tais como cartas e biografias dos personagens proeminentes da política - que se pode conhecer melhor o período de transição política entre República e Império. A autora tece uma crítica aos estudos revisionistas das biografias dos imperadores, pois tais estudos desviam a atenção de questões principais da estrutura essencial da história romana e seus desdobramentos. Ela argumenta que estudar as qualidades e personalidades individuais de cada imperador pouco esclarece sobre o modelo básico de governo imperial (p. 407).

Após tal ponderação, a autora destaca os problemas do "modelo augustiniano", que se configura em conflitos definidores do poder imperial, como: a sucessão, o relacionamento com o Senado e o status do imperador, divino ou não. Esses problemas permearam toda a estrutura de poder no período do Império e são cruciais para entender seu funcionamento, mais do que o conhecimento das histórias de crimes, conspirações e ações temperamentais dos imperadores.

Para se produzir conhecimento plausível sobre o poder político romano, é necessário desvendar os caminhos das construções, campanhas militares e generosas benemerências, conjugando as problemáticas suscitadas pelos conflitos sucessórios e pelas lutas de poder entre o Senado e o Imperador com a crescente distanciação da imagem do "primeiro entre os iguais", bem como com a aproximação do Imperador a uma divindade.

Em meio a tal releitura da história política, a autora é perspicaz em mesclar sua escrita com detalhes e curiosidades interessantes, não só da política, mas também dos costumes, da religião e da cultura da época. Em um mundo em que a guerra era o princípio estruturante da história e a religião subscrevia o poder, a realidade era substancialmente diferente da atual.

$S P Q R$ oferece, assim, uma vívida versão da história de Roma. Mas a obra também nos fornece um vislumbre do que é possível saber sobre a vida cotidiana dentro e fora de Roma, nas províncias, sobre como viviam, trabalhavam e se divertiam todos os grupos sociais. Com clareza e precisão, a autora engendra uma história da Roma Antiga que instiga o leitor a imaginar, questionar e interpretar os fatos: como viviam os romanos, como conduziam a política e como lidavam com seus problemas pessoais? Analisando uma variada fonte documental que vai de documentos escritos em pedras e papiros a vestígios arqueológicos de todos os tipos apresentados em mais de cem ilustrações, sua narração eloquente e admiravelmente matizada por um olhar desconfiado sobre os fatos leva a desmistificar os acontecimentos narrados nas maquinações cotidianas das grandes figuras políticas, nas barganhas e negociações, nos problemas financeiros e familiares, nas situações contundentes entre filhos e escravos, o que torna seu trabalho extremamente envolvente.

O desfecho da obra analisa o final do primeiro milênio da Roma Antiga, partindo do momento em que Caracala, em 212 d. C., transforma todo cidadão livre em romano por direito. A autora associa esse fato aos motivos pelos quais Roma cresceu e sustentou 
sua posição por tanto tempo, uma vez que essa decisão fez com que a diferença entre conquistador e conquistado passasse a inexistir, e um processo de expansão dos deveres, direitos e privilégios conferidos ao cidadão romanos se iniciasse. Mas o decreto de cidadania foi apenas uma das muitas transformações, rupturas, crises e invasões que mudaram o mundo romano entre os séculos III e V d. C., o que tornou a passagem do mundo Clássico ao Medieval marcado pelo esvaziamento - mas não pelo esquecimento - da profética conquista do mundo pelos romanos anunciada na Eneida de Virgílio: o Império mundial de Roma parecia, nesse momento, ter limites.

É descrevendo um contexto de intensas transformações que Mary Beard finaliza sua obra. Infelizmente, declara não tencionar produzir outro volume. Entretanto, SPQR oferece uma boa introdução para aqueles que querem estudar o que foi esse fenômeno - o Império Romano -, como se expandiu e permaneceu no poder por tanto tempo, o que pode ser apreendido dessa experiência, o que se pode entender sobre a noção de cidadania romana, suas práticas políticas, sua retórica, suas leis.

Numa tentativa de escrever para todos os públicos, abarcando um longo período da história e abrangendo vários domínios do conhecimento, $S P Q R$ procura desmistificar a concepção de que havia apenas uma Roma. Ao longo da obra, a autora demonstra que não se podem analisar as especificidades da magnitude da dominação romana com os mesmos pressupostos com que se analisa o Império central concentrado na Península Itálica - como se Roma funcionasse de forma homogênea nas diversas partes do extenso território a que se expandiu.

Apesar de a autora não fazer uso de notas de rodapé, ao final da obra apresenta uma longa lista de sugestões de leituras e desenvolve comentários sobre cada assunto para aqueles que desejarem complementar ou aprofundar os estudos em temas específicos. No corpo da obra, não há referências a outras pesquisas. Mesmo assim, ela é capaz de desenvolver argumentações sobre a maioria das modernas descobertas arqueológicas e as mais recentes revisões historiográficas. Assim sendo, aos que se interessam por conhecer uma história desse Império a fim de entender suas influências sobre a cultura Ocidental, SPQR: Uma história da Roma Antiga consiste em um material esclarecedor. De linguagem simples, mas não simplista, proporciona uma leitura extremamente agradável, sem prejuízo de seu mérito acadêmico. 